09,14

Время жизни колебательных состояний молекул ДНК в функционализированных комплексах полупроводниковых

\title{
квантовых точек
}

(C) Ф.Б. Байрамов ${ }^{1,2}$, Е.Д. Полоскин ${ }^{2}$, А.Л. Чернев ${ }^{1}$, В.В. Топоров ${ }^{2}$, M.B. Дубина ${ }^{1}$, C. Sprung ${ }^{3}$, H.K. Lipsanen ${ }^{4}$, Б.X. Байрамов ${ }^{2, \uparrow}$

${ }^{1}$ Санкт-Петербургский академический университет -

Научно-образовательный центр нанотехнологий РАН, Санкт-Петербург,

Россия

${ }^{2}$ Физико-технический институт им. А.Ф. Иоффе РАН, Санкт-Петербург,

Россия

${ }^{3}$ Fritz Haber Institute, Max Planck Society, Department of Inorganic

Chemistry, Berlin, Germany

${ }^{4}$ Department of Micro- and Nanosciences, Micronova, Aalto University, Aalto,

Finland

^E-mail: bairamov@mail.ioffe.ru

Поступило в Редакцию 20 сентября 2017 г.

На примере $n c-\mathrm{Si} / \mathrm{SiO}_{2}$, функционализированных короткими олигонуклеотидами, показано, что комплексы изолированных полупроводниковых кристаллических квантовых точек представляют собой уникальные объекты для обнаружения особенностей проявления новых квантово-размерных эффектов. Установлено, что обнаружение узких спектральных линий в спектрах неупругого рассеяния света высокого спектрального разрешения позволяет определить характерный масштаб времен колебательных возбуждений отдельных молекул нуклеотидов и дает возможность изучения структурно-динамических свойств быстропротекающих колебательных процессов в биомакромолекулах.

DOI: $10.21883 /$ PJTF.2018.02.45467.17050

Быстро развиваемые направления нанобиотехнологий для нанобиофотоники и наномедицины стимулируют повышенный интерес к созданию и исследованиям нового класса низкоразмерных наноструктур - нанобиогибридных комплексов полупроводниковых квантовых 
точек, функционализированных молекулами нуклеиновых кислот. Такие структуры имеют большое значение для наноконструирования самых разных гибридных устройств. Особое внимание к этому классу материалов также связано с важным значением в нашей жизни и самих биомакромолекул, в частности олигонуклеотидов, являющихся фрагментами дезоксирибонуклеиновых (ДНК) или рибонуклеиновых (РНК) кислот. Вследствие этого изучение механизмов взаимодействия между отдельными атомами, молекулами и функциональными группами самих олигонуклеотидов, а также зависимостей этих механизмов от физико-химических свойств окружающей среды представляется весьма значимым. Особый интерес вызывают ранее неизученные молекулярные механизмы ковалентного связывания отдельных молекул ДНК с неорганическими полупроводниковыми наноструктурами. В первую очередь это обусловлено уникальными флуоресцентными свойствами полупроводниковых квантовых точек (ПКТ). Все это позволяет создавать эффективные аналитические и биомедицинские диагностические методики, средства адресной доставки лекарственных препаратов к клеткам-мишеням.

Без фундаментальных структурных исследований и детального понимания физических процессов, протекающих как в отдельности (в исходных системах - полупроводниковых квантовых точках), так и в белковых молекулах, ДНК, а также и в целостной функционализированной структуре [1-8], невозможно успешное развитие указанных выше направлений нанотехнологий. При этом одной их актуальных задач является необходимость совершенствования и разработки новых эффективных методов исследования таких структур на молекулярном уровне. Одним из эффективных аналитических методов исследования структуры таких сложных систем на молекулярном уровне является спектроскопия неупругого рассеяния света. ПКТ $n c-\mathrm{Si} / \mathrm{SiO}_{2}$ благодаря их уникальным физическим и химическим свойствам, в частности высокому квантовому выходу и возможности перестройки длины волны фотолюминесценции в широком спектральном видимом диапазоне спектра [5-8], а также биосовместимости с организмом человека, представляют большой интерес.

В настоящей работе приводятся результаты исследования функционализации ПКТ $n c-\mathrm{Si} / \mathrm{SiO}_{2}$ одноцепочечными короткими олигонуклеотидами на примере системы $\mathrm{d}(20 \mathrm{G}, 20 \mathrm{~T})$. Здесь $\mathrm{d}-$ дезоксирибо-

Письма в ЖТФ, 2018, том 44, вып. 2 


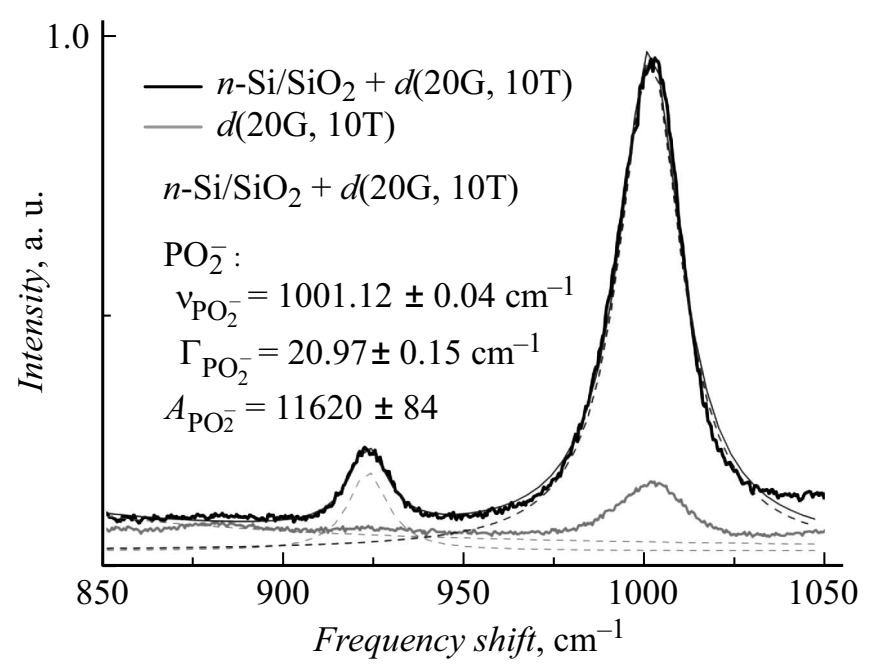

Рис. 1. Экспериментальные спектры комбинационного рассеяния света в комплексах квантовых точках $n c-\mathrm{Si} / \mathrm{SiO}_{2}$, функционализированных олигонуклеотидами $\mathrm{d}(20 \mathrm{G}, 20 \mathrm{~T})$, и в самих олигонуклеотидах $\mathrm{d}(20 \mathrm{G}, 20 \mathrm{~T})$, обнаруженные в диапазоне частот $850-1050 \mathrm{~cm}^{-1}$. Спектры получены при комнатной температуре. Спектральное разрешение составляло $2 \mathrm{~cm}^{-1}$.

нуклеотиды, G и T - нуклеотиды гуанин и тимин соответственно. Экспериментальные исследования выполнены с помощью развитой методики спектроскопии комбинационного рассеяния света высокого спектрального и пространственного разрешений, а также высокой чувствительности регистрации спектров. Они позволили обнаружить сложные спектры таких комплексов и, что особенно важно, выявить узкие спектральные линии, соответствующие отдельным молекулам олигонуклеотидов. Показано, что обнаружение узких спектральных линий в спектрах неупругого рассеяния света позволяет определить характерный масштаб времен колебательных возбуждений отдельных молекул нуклеотидов и дает возможность изучения динамики быстропротекающих колебательных процессов в биомакромолекулах.

Типичные спектры комбинационного рассеяния света в диапазоне частот $850-1050 \mathrm{~cm}^{-1}$ в квантовых точках $n c-\mathrm{Si} / \mathrm{SiO}_{2}$, функционализи-

Письма в ЖТФ, 2018, том 44, вып. 2 


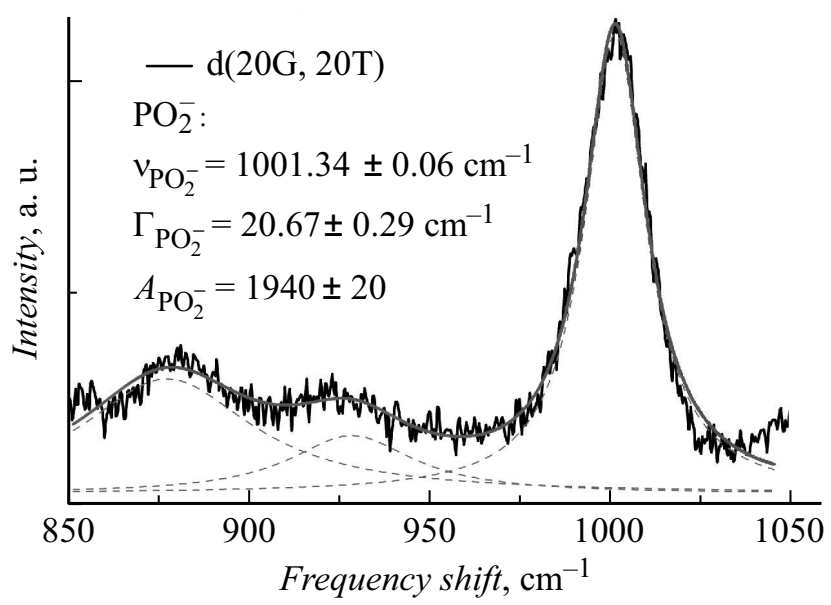

Рис. 2. Экспериментальный спектр комбинационного рассеяния света в олигонуклеотидах d $(20 \mathrm{G}, 20 \mathrm{~T})$ в диапазоне частот $850-1050 \mathrm{~cm}^{-1}$. Спектры получены при комнатной температуре. Спектральное разрешение составляло $2 \mathrm{~cm}^{-1}$.

рованных олигонуклеотидами $\mathrm{d}(20 \mathrm{G}, 20 \mathrm{~T})$, и в самих исходных олигонуклеотидах d(20G, 20T) приведены на рис. 1 и 2. Спектры получены при одинаковых экспериментальных условиях (температура, геометрия рассеяния, длина волны, плотность мощности возбуждающего излучения и т.п.). Обнаруженные для оптимизированных структур комплексов квантовых точек $n c-\mathrm{Si} / \mathrm{SiO}_{2}$ и олигонуклеотидов $\mathrm{d}(20 \mathrm{G}, 20 \mathrm{~T})$ экспериментальные результаты демонстрируют, что достигнутые высокое спектральное и пространственное разрешение и высокая чувствительность методики регистрации спектров комбинационного рассеяния света оказались достаточными для выделения спектральных составляющих, соответствующих колебаниям отдельных молекул олигонуклеотидов, и выявления изменений их относительных интенсивностей. Спектры последних определяются пространственной структурой, задаваемой большим числом входящих в ее примитивную ячейку атомов, совершающих колебания относительно положений равновесия. Макромолекулы коротких олигонуклеотидов, как и макромолекулы белков, не содержат ни центров инверсии, ни зеркальной симметрии. В целом структурное

Письма в ЖТФ, 2018, том 44, вып. 2 
упорядочение биологических систем, в частности олигонуклеотидов, является результатом низкой симметрии их элементарных ячеек, обладающих винтовой или хиральной асимметрией [9]. В спектрах комбинационного рассеяния света таких макромолекул должны наблюдаться сильно перекрывающиеся спектральные вклады, генерируемые большим набором атомов. Изменения спектральных параметров должны наблюдаться и для всех функциональных групп, испытывающих также влияние парных взаимодействий и окружающей среды. Полученные результаты показывают, что одной из наиболее важных особенностей являются высокая воспроизводимость и обнаружение удивительно узких спектральных линий и в спектрах олигонуклеотидов d(20G, 20T) [10,11], и в комплексах квантовых точек $n c-\mathrm{Si} / \mathrm{SiO}_{2}$, функционализированных такими олигонуклеотидами. Так, одна из наиболее узких и интенсивных линий, приписываемая фосфатным группам $\mathrm{PO}_{2}^{-}$сахарофосфатного остова олигонуклеотида [11], испытывает довольно неожиданное существенное усиление интенсивности, когда площадь под кривой рассеяния $A$ увеличивается с 1940 до 11620 соответственно. При этом обнаруживаются одинаковые значения и частоты $v$, и полуширины линии Г как в спектрах олигонуклеотидов $\mathrm{d}(20 \mathrm{G}, 20 \mathrm{~T})$ с $v=1001.34 \pm 0.06 \mathrm{~cm}^{-1}$, $\Gamma=20.67 \pm 0.29 \mathrm{~cm}^{-1}$, представленных на рис. 2, так и в спектрах комплексов ПКТ $n c-\mathrm{Si} / \mathrm{SiO}_{2}$, функционализированных олигонуклеотидами, с $v=1001.12 \pm 0.04 \mathrm{~cm}^{-1}, \Gamma=20.97 \pm 0.15 \mathrm{~cm}^{-1}$. Наблюдаемое существенное сужение ширины линии (в 2-3 раза) по сравнению со спектрами, полученными для водного раствора олигонуклеотидов, позволило надежно выделить лоренцевскую форму этой узкой линии с полушириной $\Gamma=1 / 2 \pi c \tau$, где $c-$ скорость света, $\tau-$ время жизни возбуждения. Непосредственное измерение естественной полуширины дает возможность впервые определить временной масштаб элементарных колебательных возбуждений в биомакромолекулах. Для измеренного значения полуширины $\Gamma=20.67 \pm 0.29 \mathrm{~cm}^{-1}$ соответствующее время жизни для валентных колебаний фосфатных групп $\mathrm{PO}_{2}^{-}$сахарофосфатного остова с учетом вкладов на ангармонические взаимодействия при комнатной температуре оказалось равным $\tau=0.26 \pm 0.15 \mathrm{ps}$. Такое измерение, в частности, позволяет установить временной масштаб элементарных колебательных возбуждений молекулярных групп в нанокомплексах ПКТ $n c-\mathrm{Si} / \mathrm{SiO}_{2}$, функционализированных олигонуклеотидами. Наряду с этим оно позволяет сделать важный нетривиальный вывод, поскольку прямо указывает на сохранение в таких комплексах временно́го

Письма в ЖТФ, 2018, том 44, вып. 2 
масштаба элементарных колебательных возбуждений, определенного для самих олигонуклеотидов d $(20 \mathrm{G}, 20 \mathrm{~T})$. Таким образом, обнаружение узких спектральных линий делает возможным экспериментальное исследование внутренних динамических свойств быстропротекающих процессов колебательных движений атомов в комплексах квантовых точек, функционализированных биомакромолекулами. Измеренная величина естественной полуширины линий и/или времени жизни колебательных состояний может также служить надежной мерой специфичности и степени совершенства молекулярной структуры таких комплексов.

Работа выполнена при финансовой поддержке программ Президиума РАН „Наноструктуры: физика, химия, биология, основы технологий“ и „Актуальные проблемы фотоники, зондирование неоднородных сред и материалов“, а также проекта „Granbis““ Агентства финансирования технологий и инноваций TEKES (Финляндия).

\section{Список литературы}

[1] Bairamov B.H., Toporov V.V., Bayramov F.B., Lanzov V., Dutta M., Stroscio M.A., Irmer G. // J. Phys.: Conf. Ser. 2007. V. 93. P. 012046.

[2] Bairamov B.H., Toporov V.V., Bayramov F.B., Vasidev M., Dutta M., Stroscio M.A., Irmer G. // Proc.of the Int. Federation for Medical and Biological Engineering. N. Y.: Springer, 2008. V. 20. P. 594-597.

[3] Bayramov F.H., Irmer G., Toporov V.V., Bairamov B.H. // Jpn. J. Appl. Phys. 2011. V. 50. P. 05FE06.

[4] Байрамов Ф.Б., Топоров В.В., Полоскин Е.Д., Байрамов Б.X., Rödеr C., Sprung C., Bohmhammel G., Seidel K., Irmer G., Lashkul A., Lahderanta E., Song Y.W. // ФТП. 2013. Т. 47. В. 5. С. 607-612.

[5] Маслова Н.Е., Антоновский А.А., Жигунов Д.М., Тимошенко В.Ю., Глебов В.Н., Семиногов В.Н. // ФТП. 2010. Т. 44. В. 8. С. 1074-1077.

[6] Володин В.А., Сачков В.А. // ЖЭТФ. 2013. 143. В. 1. С. 100-108.

[7] Marnix H., Medema M.H., Raaphorst R., Takano E., Breitling R. // Nature Rev. Microbiol. 2012. V. 10. P. 191-202.

[8] Тимошенко В.Ю., Кудрявщев А.А., Осминкина Л.А., Воронщов А.С., Рябчиков Ю.В., Белогорохов И.А., Ковалев Д., Кашкаров П.К. // Письма в ЖЭТФ. 2006. Т. 83. В. 9. С. 492-495.

Письма в ЖТФ, 2018, том 44, вып. 2 
[9] Kitaev Yu.E., Panfilov A.G., Smirnov V.P., Tronc P. // Phys. Rev. E. 2003. V. 67. P. 011907.

[10] Байрамов Ф.Б., Полоскин Е.Д., Чернев А.Л., Топоров В.В., Дубина М.В., Лахдеранта Е., Липсанен Х., Байрамов Б.Х. // Письма в ЖЭТФ. 2014. V. 99. B. 7. C. 437-442.

[11] Байрамов Б.Х. // ФТТ. 2016. Т. 56. В. 4. С. 707-713. 